\title{
Peran Keluarga Terhadap Perilaku Mahasiswa yang Mengkonsumsi Minuman Beralkohol di Kabupaten Jember
}

\section{(Role of Family to Student Behavior that Consume Alcohol Drink in Jember District)}

\author{
Nina Ainur Rahma ${ }^{1}$, Husni Abdul Gani², Mury Ririanty ${ }^{3}$ \\ Bagian Promosi kesehatan dan IImu Perilaku Fakultas Kesehatan Masyarakat Universitas Jember \\ Jln. Kalimantan 37 Kampus Tegal Boto Jember 68121 \\ e-mail: ninaainur919@gmail.com
}

\begin{abstract}
Adolescents in the age range of 17-21 years are generally students, who are expected to have good cognitive skills and be able to solve problems effectively. Teenagers who are unable to solve problems sometimes do something that is harmful to themselves such as consuming alcoholic beverages. The role of the family such as parenting and family conditions is one of the causes of adolescents consuming alcoholic beverages. This study aims to determine the role of families in the behavior of students who consume alcoholic beverages in Jember Regency. The theory used by researchers is Social Learning from Bandura. This research is a descriptive study with a qualitative approach. Determination of research informants using snowball techniques. Data collection uses in-depth interviews, documentation and passive participatory observation. Based on the results of the study it was found that the all-free parenting style, lack of trust given by parents to involve children in making decisions and ineffective time spent by parents for families so that children behave deviant.
\end{abstract}

Keywords: Family, teenagers, alcoholic drinks, social learning

\begin{abstract}
Abstrak
Masa remaja dalam rentang usia 17-21 tahun umumnya sedang berstatus mahasiswa, diharapkan memiliki kognitif baik dan mampu menyelesaikan masalah secara efektif. Remaja yang tidak mampu menyelesaikan masalah terkadang melakukan sesuatu yang merugikan bagi dirinya sendiri seperti mengkonsumsi minuman beralkohol. Peran keluarga seperti pola asuh dan kondisi keluarga menjadi salah satu penyebab remaja mengkonsumsi minuman beralkohol. Penelitian ini bertujuan untuk mengetahui peran keluarga terhadap perilaku mahasiswa yang mengkonsumsi minuman beralkohol di Kabupaten Jember. Teori yang digunakan oleh peneliti adalah Belajar Sosial dari Bandura. Penelitian ini merupakan penelitian deskriptif dengan pendekatan kualitatif. Penentuan informan penelitian menggunakan teknik snowball. Pengumpulan data menggunakan wawancara mendalam, obsevasi partisipatif pasif, dokumentasi dan triangulasi sumber. Berdasarkan hasil penelitian diketahui bahwa gaya pengasuhan yang serba membebaskan, kurangnya kepercayaan yang diberikan orang tua untuk melibatkan anak dalam mengambil keputusan dan kurang efektifnya waktu yang diluangkan orang tua untuk keluarga sehingga anak berperilaku menyimpang.
\end{abstract}

Kata Kunci: Keluarga, remaja, minuman beralkohol, belajar sosial 


\section{Pendahuluan}

Masa remaja dalam rentang usia 17-21 tahun umumnya sedang berstatus mahasiswa. $\mathrm{Di}$ masa perkembangan remaja memiliki sifat khas yaitu rasa ingin tahu yang tinggi, dari sifat keingintahuannya yang tinggi remaja cenderung menyukai hal yang menantang bahkan dapat membahayakan dirinya sendiri tanpa disadari sebelumnya. Remaja yang tidak mampu menyelesaikan masalah terkadang melakukan sesuatu yang merugikan bagi dirinya sendiri seperti mengkonsumsi minuman beralkohol [1]. Remaja yang awalnya hanya penasaran dengan minuman beralkohol, akibatnya ketika mencoba mengkonsumsi minuman beralkohol menjadi kecanduan karena pengaruh zat-zat yang terdapat pada minuman beralkohol tersebut [2].

Berdasarkan Peraturan Menteri Perdagangan Republik Indonesia No. 20 Tahun 2014 Pasal 2, dibagi minuman beralkohol dibagi menjadi tiga golongan yaitu golongan $\mathrm{A}$ yang mengandung etil alkohol atau etanol $\left(\mathrm{C}_{2} \mathrm{H}_{5} \mathrm{OH}\right)$ dengan kadar $5 \%$, golongan $\mathrm{B}$ dengan kadar etil alkohol atau etanol $\left(\mathrm{C}_{2} \mathrm{H}_{5} \mathrm{OH}\right)$ lebihdari $5 \%-20 \%$ dan golongan $\mathrm{C}$ minuman beralkohol yang mengandung etil alkohol atau etanol $\left(\mathrm{C}_{2} \mathrm{H}_{5} \mathrm{OH}\right)$ dengan kadar lebih dari 20\%-55\% [3]. Direktur Bina Kesehatan Jiwa Kementerian Kesehatan RI, dr. Eka Viora, Sp.J (K), menjelaskan bahwa terdapat perbedaan jenis alkohol pada miras oplosan dengan jenis alkohol pada minuman beralkohol yang biasa dikonsumsi manusia, pada minuman beralkohol yang biasa dikonsumsi manusia merupakan etil alkohol atau etanol, sedangkan jenis alkohol pada miras ialah metyl alkohol atau methanol yang dapat menyebabkan kematian [4].

Data yang dimiliki Badan Narkotika Nasional dan POLRI pada tahun 2013 dalam lima tahun terakhir kategori zat adiktif jumlah kasusnya menurun, dapat dilihat pada tahun 2009 jumlah kasus psikotropika 8.779 kasus dan mengalami penurunan pada tahun 2010 menjadi $1.181 \mathrm{ka}-$ sus. Pada tahun 2010-2012 provinsi Jawa Timur berada di posisi pertama tingkat provinsi dengan jumlah kasus narkoba sebanyak 6.395 tersangka pada tahun 2010 dan meningkat menjadi 8.142 tersangka pada tahun 2012 [4].

Data Satuan Polisi Pamong Praja (Satpol PP) Kabupaten Jember menunjukkan jumlah kasus razia miras terjadi peningkatan pada tahun 2015-2016, ditahun 2015 terdapat 19 kasus merupakan remaja yang terlibat razia miras dan di tahun 2016 remaja dengan rentang usia 17-21 tahun yang terlibat kasus razia miras meningkat menjadi 20 kasus [5]. Data pengungkapan miras yang dilakukan oleh Satuan Sabhara Polres Jember pada tahun 2016 terdapat 162 kasus tersangkanya kelompok umur $\geq 18$ tahun dan terdapat 68 kasus yang tersangkanya kelompok umur $\leq 18$ tahun, mengalami penurunan jumlah kasus pengungkapan miras pada tahun 2017 dari bulan Januari hingga bulan Juli yaitu sebanyak 104 kasus dengan tersangka kelompok umur $\geq 18$ tahun dan sebanyak 41 kasus yang tersangkanya kelompok umur $\leq 18$ tahun [6].

Hasil studi pendahuluan yang dilakukan peneliti di Satuan Polisl Pamong Praja (Satpol PP) Kabupaten Jember, didapatkan bahwa yang menjadi faktor pendorong remaja melakukan perilaku mengkonsumsi minuman beralkohol ialah faktor internal dan faktor eksternal. Jenis keluarga yang tidak utuh dan terdapat seorang remaja sedang tumbuh dewasa sangat mempengaruhi tingkah lakunya dan lebih berpotensi menyalahgunakan alkohol daripada yang tinggal dengan keluarga utuh [7].

Berdasarkan latar belakang yang diuraikan diatas, maka rumusan masalah yang akan dikaji dalam penelitian ini yaitu mengenai bagaimana karakteristik dan sikap mahasiswa yang mengkonsumsi minuman beralkohol dan bagaimana peran keluarga yang meliputi tuntutan pengasuhan, keterlibatan keluarga dan komitmen waktu keluarga terhadap mahasiswa yang mengkonsumsi minuman beralkohol. Sehingga penelitian ini diberi judul "Peran Keluarga Terhadap Perilaku Mahasiswa Yang Mengkonsumsi Minuman Beralkohol di Kabupaten Jember".

\section{Metode Penelitian}

Penelitian ini merupakan penelitian deskriptif dengan pendekatan kualitatif yang dilaksanakan di daerah kampus universitas negeri dan swasta yang terdapat di Kabupaten Jember. Penelitian dilakukan pada bulan Agustus 2018 sampai dengan selesai. Informan penelitian merupakan mahasiswa yang masih dalam kelompok umur remaja akhir yaitu dengan rentang usia 18-21 tahun yang ditentukan menggunakan teknik snowball. Peneliti mengumpulkan data menggunakan wawancara mendalam, obsevasi partisipatif pasif, dokumentasi dan triangulasi sumber. Teknik analisis data menggunakan analisis data berlangsung atau mengalir (flow model analysis) dan disajikan dalam bentuk narasi. 


\section{Hasil dan Pembahasan}

\section{Gambaran Karkateristik Informan}

Informan dalam penelitian ini terdiri dari enam informan, yaitu tiga informan utama dan tiga informan tambahan. Seluruh informan bertempat tinggal di sekitar lingkungan universitas negeri dan swasta yang terdapat di Kabupaten Jember. Latar belakang pendidikan informan seluruhnya ialah merupakan mahasiswa kelompok umur remaja akhir yaitu dalam rentang usia 19-21 tahun dengan jenis kelamin dua orang perempuan dan satu orang laki-laki. Gambaran karakteristik informan menunjukkan sifat khas yang dimiliki remaja yaitu rasa ingin tahu yang tinggi dan kurangnya kepercayaan diri. Model pergaulan remaja perempuan tidak terdapat perbedaan dengan model pergaulan laki-laki, karena kebiasaan dalam pergaulan dari remaja perempuan tidak berbeda jauh dengan remaja laki-laki. Remaja yang memiliki sikap percaya diri tinggi maka ia dapat mengontrol diri agar terhindar dari kenakalan remaja. Karena potensi diri yang berdampak pada diri sendiri dan lingkungannya dipengaruhi oleh sikap percaya diri [8].

\section{Sikap Penyalahgunaan Minuman Be- ralkohol di Kalangan Mahasiswa Kabu- paten Jember}

Sikap seseorang terhadap suatu objek merupakan perilaku yang tidak dapat dilihat jelas oleh orang lain, yang sudah melibatkan faktor pendapat dan emosi yang bersangkutan (senang-tidak senang, setuju-tidak setuju, baiktidak baik, dan sebagainya) [9]. Berikut pernyataan informan mengenai mengenai perasaan ketika mengkonsumsi minuman beralkohol:

"Sebenernya awalnya ya saya aneh mbak, kenapa minuman yang rasanya gitu pait aneh lah menurut saya bisa banyak yang suka gitu. Tapi sekarang malah ketagihan, pahitnya itu sudah biasa" (IU1, 26 Agustus 2018)

Sebagian kecil pernyataan informan timbul rasa senang disebabkan karena adanya persepsi bahwa informan merasa tenang dan tidak memiliki beban masalah ketika mengkonsumsi minuman beralkohol. Remaja yang ikut-ikutan mengkonsumsi minuman keras hanya ingin mendapatkan pengakuan dari kelompok dan kepercayaan diri mereka meningkat setelah mengkonsumsi minuman keras [10]. Berikut merupakan pernyataan informan:

"Soalnya diajak teman itu mbak, ga enak kan kalau nolak, terus saya juga pengen nyoba kan awalnya" (IU2, 26 Agustus 2018)

Hal ini juga menunjukan bahwa informan tidak memiliki sikap intelektual yang baik karena informan tidak memiliki bekal berkomitmen dalam pengendalian diri untuk menolak ajakan temannya. Dengan dapat berkomitmen dalam mengendalikan dirinya sendiri, manusia tidak akan dipandang sebelah mata sebagai seseorang yang tidak bermanfaat bagi sekitar karena tidak dapat mengontrol diri dan mudah terpengaruh lingkungan [11].

\section{Peran Keluarga}

a. Tuntutan Pengasuhan

Tuntutan pengasuhan tertinggi terjadi pada orang tua yang memiliki anak dalam rentang usia dua sampai dengan 22 tahun [12]. Berikut kutipan informan mengenai tipe pengausuhan yang diterapkan orang tua/wali:

"Sikap tante yang tinggal

sama saya baik, saya mau berteman dengan siapapun ga masalah ga ngelarang gitu. Kalau orang tua saya dari dulu cuek aja terserah saya mau berteman dengan siapa" (IU3, 28 Agustus 2018)

Pernyataan informan menunjukkan bahwa tidak ada hukuman atau sanksi dari orang tua/wali jika informan melanggar aturan atau melakukan kesalahan. Kurangnya dukungan dari orang tua mengenai penanaman karakter pada anak yang membuat anak kurang siap dalam mengontrol diri untuk menghadapi masalah sosial dimasa remaja [13].

Anak-anak yang dibesarkan oleh orang tua dengan gaya pengasuhan permissive-indifferent juga cenderung memiliki kepribadian yang buruk seperti kurang percaya diri, pengendalian diri yang tidak baik, dan rasa harga diri yang rendah dalam menjalankan kehidupan di masyarakat. Berikut merupakan kutipan pernyataan informan mengenai sikap orang tua:

"Biasa aja sih mbak, sering tengkar gara-gara beda pendapat. Bahkan saya sampai merasa kurang mendapat kasih sayang karena orang tua saya cuek" (IU3, 28 Agustus 2018)

Sebagian kecil informan merasa kurang mendapatkan perhatian, sering berselisih pendapat dengan orang tua, serta kurang kondisifnya kondisi rumah. Kondisi keluarga 
yang tidak utuh lebih berpotensi menyebabkan anak laki-laki dan perempuan menyalahgunakan alkohol dibandingkan yang tinggal dengan keluarga yang utuh [8].

b. Komitmen Waktu Keluarga

Komitmen waktu keluarga merupakan tanggung jawab orang tua terhadap anggota keluarga terutama terhadap anak karena tuntutan peran seseorang dalam keluarga yang dicerminkan dari total meluangkan waktu untuk melakukan pekerjaan rumah tangga dan mendidik anak [12]. Berikut pernyataan informan mengenai cara orang tua/wali meluangkan waktu untuk keluarga:

"Kalau kumpul sama keluarga, pas ibu pulang ke rumah cuma sekedar kumpul di rumah gitu setelah maghrib duduk-duduk nonton tv ngobrol biasa" (IU1, 26 Agustus 2018)

"Cuma ngumpul biasa aja di rumah, ngobrol-ngobrolin yang ada di tv sambil nonton tv gitu" (IU2, 26 Agustus 2018)

Sebagian besar informan menyatakan ketidak efektifan komunikasi antara orang tua dengan informan membuat informan merasa kurang mendapatkan perhatian dari orang tua. Peran komunikasi dalam menanggulangi kenakalan remaja berkaitan dengan kesibukan dan ego orang tua yang dapat berdampak kepada anak mempunyai konsep diri yang negatif [14].

Kurangnya perhatian dari orang tua terhadap anak merupakan faktor yang sangat berpengaruh terhadap munculnya kenakalan remaja [15]. Informan utama menyatakan bahwa ketidakpuasan atas waktu yang diluangkan oleh orang tua karena status orang tua sebagai single parents dan kesibukan orang tua yang harus merantau keluar pulau untuk mencari nafkah. Status sosial ekonomi pada sebuah keluarga mempengaruhi intensitas komunikasi antar anggota keluarga terutama seorang istri dengan suami dan anak [16].

\section{Perilaku Mengkonsumsi Minuman Beralko- hol Pada Mahasiswa}

a.Tempat Dan Waktu Mengkonsumsi Minuman Beralkohol

Perubahan atau adopsi perilaku baru dalam kehidupan seseorang melalui beberapa tahap, salah satunya yaitu sikap. Mewujudkan sikap dalam tindakan diperlukan faktor eksternal seperti fasilitas dan prasarana [9]. Berikut kutipan pernyataan informan mengenai sarana prasaran yang sudah tersedia untuk mengkonsumsi minuman beralkohol: "di kost kadang di club atau di tempat karaoke kalau ada yang traktiran ulang tahun. Dak bingung lah mbak kalau soal tempat yang aman" (IU1, 26 Agustus 2018)

"Kadang di club (tempat hiburan malam), tempat karaokean, kan saya sambil kerja di tempat karaoke mbak, kadang minum di kost teman. Ada tempatnya lah mbak" (IU2, 26 Agustus 2018)

Berdasarkan hasil penelitian, menunjukkan bahwa sebagian besar pernyataan informan tersedianya fasilitas seperti tempat karaoke dan hiburan malam membuat informan sangat mudah untuk mengkonsumsi minuman beralkohol dan menjadi faktor pendukung bagi informan untuk mengkonsumsi minuman beralkohol. Hal ini sejalan dengan penelitian Senduk menunjukkan bahwa tersedianya tempat hiburan malam menjadi faktor internal atau faktor yang sangat mendukung dan memudahkan mahasiswi di Kota Manado melakukan kegiatan mengkonsumsi minuman beralkohol dan dugem [17].

b. Jenis Minuman Beralkohol Yang Dikonsumsi Mahasiswa

Jenis minuman beralkohol yang dikonsumsi oleh informan merupakan jenis alkohol golongan A dan golongan B dengan bandrol harga yang relatif murah dan mudah dijangkau informan. Informan mengkonsumsi minuman beralkohol yang harganya cukup mahal hanya ketika ditraktir oleh temannya. Berikut pernyataan informan mengenai jenis minuman beralkohol yang dikonsumsi:

"dicampur bir sama bintang ada cemilan kadang kacang atau rokok. Kadang cuma minumannya aja gitu mbak. Biasanya bir kayak bintang, vodka dicampur pepsi, atau jack daniels sama red label kalau ada yang traktiran" (IU1, 26 Agustus 2018)

Sebagian besar pernyataan informan minuman beralkohol yang dikonsumsi informan tergantung kondisi keuangan mereka dan banyak tersedia di suatu toko yang khusus menjual minuman beralkohol (kios) dan di tempat-tempat hiburan malam. Hal ini sejalan dengan penelitian Tes et al menunjukkan bahwa jenis 
minuman keras yang dikonsumsi oleh responden tergantung pada kondisi keuangan. Jenis minuman yang biasa dikonsumsi responden yaitu bir, arak atau tuak karena harganya lebih terjangkau [18].

c.Mahasiswa Mengkonsumsi Minuman Beralkohol Dilakukan Secara Individu Atau Berkelompok

Proses determinasi timbal-balik itulah terletak kesempatan bagi manusia untuk mempengaruhi nasibnya maupun batas-batas kemampuannya untuk memimpin diri sendiri [11]. Informan mengkonsumsi minuman beralkohol dilakukan bersama teman beda kampus, pacar dan dikonsumsi sendirian. Berikut pernyataan informan mengenai hal tersebut:

"Yang paling sering diajak sama temen kost, sama pacar, diajak temen kuliah tapi beda kampus mbak" (IU1, 26 Agustus 2018)

"kalau diajak pacar ya minum sama pacar sama temen-temennya dia juga, sama teman, sama tamu saya. Kadang saya minum sendirian mbak kalau temen-temen malas minum gitu. Lebih sering minum sama teman sih" (IU3, 28 Agustus 2018)

Sebagian kecil informan mengkonsumsi minuman beralkohol dilakukan sendirian jika tidak ada teman yang mengajaknya, namun jika mendapat ajakan dari temannya informan mengkonsumsi bersama temannya. $\mathrm{Hal}$ ini sejalan dengan penelitian Senduk, ajakan teman atau kenalan dan karena rasa penasaran dengan suasana dunia gemerlap serta kegiatan di dalamnya yaitu mengkonsumsi minuman beralkohol, sehingga remaja mau terjun ke dunia gemerlap [17].

Minuman beralkohol di dalamnya terdapat kandungan etanol, yang dapat menurunkan tingkat kesadaran bagi penggunanya (mabuk) dan mengandung zat adiktif yang dapat menyebabkan kecanduan bagi penggunanya serta mempengaruhi sistem kerja otak. Dampak kesehatan mengkonsumsi minuman beralkohol menyebabkan gangguan kesehatan fisik dan gangguan terhadap mental [19]. Berikut pernyataan informan terkait dampak kesehatan yang dirasakan setelah mengkonsumsi minuman beralkohol:

"Setelah minum pusing gitu mbak. Sering dak bisa ngontrol emosi, gampang tersinggung karena hal kecil gitu mbak" (IU1, 26 Agustus 2018)

"Ngerusak badan juga, asam lambung saya sering naik mbak langsung pusing gitu setelah minum itu" (IU3, 28 Agustus 2018)

Dampak kesehatan yang dialami seluruh informan yaitu merasa pusing setelah mengkonsumsi minuman beralkohol dan ebagian besar informan juga mengalami gangguan terhadap mental seperti mudah tersinggung dan mudah marah sehingga fungsi sosialnya terganggu. Hal ini serupa dengan penelitian Bastian dan Lukitaningsih yang menyatakan bahwa dampak dari kebiasaan mengkonsumsi minuman beralkohol akan menyebabkan gangguan mental yang mengganggu fungsi berfikir dan akan mengalami perubahan perilaku [20].

\section{Simpulan dan Saran}

Karakteristik informan utama penelitian adalah remaja akhir dalam rentang usia 19, 20 dan 21 tahun. Sikap informan menggambarkan sikap negatif karena tidak dapat mencegah dirinya sendiri agar tidak terpengaruh minuman beralkohol Sebagian besar peran keluarga dalam hal gaya pengasuhan yang diterapkan orang tua/wali dari informan ialah membebaskan anak (permissive-indulgent) dan gaya pengasuhan yang mengabaikan (permissive-indifferent). Keterbatasan serta kurangnya waktu yang diluangkan oleh orang tua untuk keluarga dan sikap orang tua/wali yang kurang bisa berempati terhadap kondisi informan sehingga kurangnya keterbukaan informan kepada orang tua. Pengaruh lingkungan dari tersedianya sarana dan prasarana seperti bebasnya peredaran minuman beralkohol, ajakan teman dan kontrol diri yang rendah membuat informan susah menjauhi minuman beralkohol dan dunianya.

Saran yang diberikan berdasarkan hasil penelitian adalah Polres (Sat. Sabhara) Jember dapat membentuk kelompok peer group untuk membantu memberikan edukasi kepada remaja agar dapat menjauhi minuman beralkohol. Satpol PP Kabupaten Jember meningkatkan pengawasan terhadap peredaran minuman beralkohol. Orang tua dan Keluarga lebih meningkatkan pengetahuan terkait ancaman minuman beralkohol, jenis bau dan warna minuman beralkohol untuk mempermudah pengawasan, dan menjalin komunikasi yang 
efektif dengan anak. Remaja diharapkan lebih selektif dalam memilih teman atau dalam berinteraksi dengan teman bergaul dan menyalurkan waktu luangnya kepada hal-hal yang lebih positif dan bermanfaat.

\section{Daftar Pustaka}

[1] Kementerian Kesehatan Republik Indonesia. 2015. Infodatin Pusat Data Informasi Kemenkes RI Situasi Kesehatan Reproduksi Remaja. Jakarta: Kemenkes RI.

[2] Willis, S. 2014. Remaja \& Masalahnya. Bandung: Alfabeta.

[3] Peraturan Menteri Perdagangan Republik Indonesia Nomor 20. 2014. Pengendalian Dan Pengawasan Terhadap Pengadaan, Peredaran, dan Penjualan Minuman Beralkohol. Jakarta: Kementerian Perdagangan Republik Indonesia.

[4] Kementerian Kesehatan Republik Indonesia. 2014. Bahaya Minuman Beralkohol Bagi Kesehatan. Jakarta: Kemenkes RI.

[5] Satuan Polisi Pamong Praja. 2017. Data Pelanggaran Perda No. 8 Tahun 2015-2017. Jember: Satuan Polisi Pamong Praja.

[6] Sat. Sabhara. 2017. Data Pengungkapan Minuman Beralkohol. Jember: Polisi Resor Kabupaten Jember.

[7] Vanassche, S., Sodermans, An., Matthijs, K. 2014. The Effects of Family Type, Family Relationships and Parental Role Models on Delinquency and Alcohol Use Among Flemish Adolscents. New York. Journal Child Fam Stud volume 23, No. 1, Januari 2014: 128-143.

[8] Fatchurahman, M., dan Pratikto, H. 2012. Kepercayaan Diri, Kematangan Emosi, Pola Asuh Orang Tua dan Kenakalan Remaja. Jurnal Psikologi Indonesia volume 1, No. 2, September 2012: 77-87.

[9] Notoatmodjo, S. 2014. IImu Perilaku Kesehatan. Jakarta: PT Rineka Cipta.

[10] Pratama, V. 2013. Perilaku Remaja Pengguna Minuman Keras di Desa Jatigono Kecamatan Kunir Kabupaten Lumajang. Jurnal Promkes FKM Universitas Airlangga volume 1, No. 2, 2013: 145-152.

[11] Priyoto. 2014. Teori Sikap dan Perilaku dalam Kesehatan. Yogjakarta: Nuha Medika.

[12] Susanti, S., dan Ekayati, I. 2013. Peran Pekerjaan, Peran Keluarga Dan Konflik Pekerjaan Pada Perawat Wanita. Jurnal Psikologi Indonesia volume 2, No.2, Mei 2013: 183-190.

[13] Kristanto, A. 2014. Bentuk Dukungan Sosial Keluarga Terhadap Remaja Pengguna Narkoba (Studi Kasus di Yayasan Borneo Insan Mandiri Samarinda). Jurnal IImu Sosiatri volume 2, No. 3, Agustus 2014: 64-76.

[14] Rogi, B. 2015. Peranan Komunikasi Keluarga Dalam Menanggulangi Kenakalan Remaja di Kelurahan Tataaran 1 Kecamatan Tondano Selatan. Jurnal Acta Diurna volume IV, No. 4, 2015 1-8.

[15] Kartono, K. 2014. Kenakalan Remaja. Jakarta: PT. RajaGrafindo Persada.

[16] Indrawati, E. 2015. Status Sosial Ekonomi dan Intensitas Komunikasi Keluarga Pada Ibu Rumah Tangga di Panggung Kidul Semarang Utara. Jurnal Psikologi Universitas Diponegoro volume 14, No. 1, April 2015: 52-57.

[17] Senduk, R. 2016. Perilaku Mahasiswi Dalam Dunia Gemerlap (Dugem) di Kota Manado. Jurnal Holistik volume 9, No. 18, Juli-Desember 2018: 1-20.

[18] Tes, A., Puspitawati, T., dan Marlinawati, V. 2017. Fenomena Perilaku Mengkonsumsi Minuman Keras Mahasiswa Program Studi S-1 Kesehatan Masyarakat Universitas Respati Yogyakarta. Jurnal Forum IImiah Kesehatan Masyarakat Respati volume 2, No.1, April 2017: 25-31

[19] Sumiati. 2009. Asuhan Keperawatan Pada Klien Penyalahgunaan dan Ketergantungan NAPZA. Jakarta: Trans Info Media.

[20] Bastian, F., dan Lukitaningsih, R. 2016. Studi Tentang Perilaku Mengkonsumsi Minuman Beralkohol pada Anak di Bawah Umur di Kecamatan Ponorogo. Jurnal BK volume 06, No. 2, 2016: 1-9. 